matozoa, p. 263-313. In J.K. Critser and A.M. Karow (Eds.), Reproductive Tissue Banking: Scientific Principles. Academic Press, San Diego, CA.

16.Corley-Smith, G.E., B.P. Brandhorst, C. Walker, and J.H. Postlethwait. 1999. Production of haploid and diploid androgenetic zebrafish (including methodology for delayed in vitro fertilization). Methods Cell Biol. 59: 45-60.

17.Naccache, P. and R.I. Sha'afi. 1973. Patterns of nonelectrolyte permeability in human red blood cell membrane. J. Gen. Physiol. 62. 714-736.

18.Mounib, M.S. 1978. Cryogenic preservation of fish and mammalian spermatozoa. J. Reprod. Fert. 228:205-218.

19.Rosner, B. 1995. Nonparametric methods, p. 551-584. Fundamentals of Biostatistics, 4th ed. Wadsworth Publishing, Belmont, CA.

20.Rosner, B. 1995. Regression and correlation methods, p. 443-549. Fundamentals of Biostatistics, 4th ed. Wadsworth Publishing, Belmont, CA.

21.Ransom, D.G. and L.I. Zon. 1999. Collection, storage, and use of zebrafish sperm. Methods Cell Biol. 60:365-372.

22.Babiak, I., J. Glowgowski, M.J. Luczynski, M. Luczynski, and W. Demanianowicz. 1999. The effect of egg yolk, low density lipoproteins, methylxanthines and fertilization diluent on cryopreservation efficiency of northern pike (Esox lucius) spermatozoa. Theriogenology. 52:473-479.

23.Baulny, B.O., C. Labbe, and G. Maisse. 1999. Membrane integrity, mitochondrial activity, ATP content, and motility of the European catfish (Silurus glanis) testicular spermatozoa after freezing with different cryoprotectants. Cryobiology 39:177-184.

24.Todo. T., T. Ikeuchi, T. Kobayashi, H. Kajiura-Kobayashi, K. Suzuki, M. Yoshikuni, K. Yamauchi, and Y. Nagahama. 2000. Characterization of a testicular 17alpha, 20beta-dihydroxy-4-pregnen-3-one (a spermiation-inducing steroid in fish) receptor from a teleost, Japanese eel (Anguilla japonica). FEBS Lett. 465:12-27.

25.Pena, A., A. Johannisson, and C. LindeForsberg. 1999. Post-thaw evaluation of dog spermatozoa using new triple fluorescent staining and flow cytometry. Theriogenology 52:965-980.

26.Wolenski, J.S. and N.H. Hart. 1987. Scanning electron microscope studies of sperm incorporation into the zebrafish (Brachydanio) egg. J. Exp. Zool. 243:259-273.

Received 18 April 2003; accepted 13 August 2003.

Address correspondence to A. Thomas Look, Department of Pediatric Oncology, Mayer-630, Dana-Farber Cancer Institute, 44 Binney Street, Boston, MA 02115, USA. e-mail: thomas_look@dfci.harvard.edu

\title{
Impact of RNA extraction from limited samples on microarray results
}

\author{
Hanna Ojaniemi ${ }^{1,3}$, Birgitta Evengard ${ }^{1}$, Daisy R. Lee ${ }^{2}$, Elizabeth R. Unger², \\ and Suzanne D. Vernon ${ }^{2}$ \\ ${ }^{1}$ Karolinska Institutet at Huddinge University Hospital, Stockholm, Sweden, \\ ${ }^{2}$ Centers for Disease Control and Prevention, Atlanta, GA, USA, and \\ ${ }^{3}$ Royal Institute of Technology, Stockholm, Sweden
}

BioTechniques 35:968-973 (November 2003)

To move microarray technology into the diagnostic realm, the impact of technical parameters, such as sample preparation and RNA extraction, needs to be understood and minimized. We evaluated the impact of two RNA extraction methods, DNase treatment and the amount of hybridized cDNA probe, on the outcome of microarray results. The results for both RNA extraction methods were comparable, although one method resulted in residual DNA that slightly affected the microarray results. As little as one microgram of total RNA could be used to synthesize a cDNA probe and resulted in a gene expression profile that was similar to one produced using $5 \mu \mathrm{g}$ total RNA, even though the overall signal intensity was lower. These experiments illustrate that microarray technology holds great promise for the use of limited clinical samples in the diagnostic setting.

\section{INTRODUCTION}

Microarray gene expression technology is an increasingly important tool in biomarker discovery. There are numerous potential clinical applications that could refine diagnosis and therapeutic monitoring as well as improve disease prevention through risk assessment and early detection. To move these platforms into the realm of in vitro diagnostics and to improve the efficiency of marker discovery, investigators need to understand and minimize the impact of biologic and technical variations on data interpretation. The numerous and potentially interrelated biologic variables in the microarray protocol include sample acquisition, extraction, labeling, hybridization, and detection. Technical variables include array design and fabrication, image acquisition, background correction, and data processing. In addition, the limited nature of the clinical samples presents challenges that must be overcome to move microarray technology into the diagnostic setting. The reproducible and reliable interpretation of microarray results depends on the use of high-quality RNA, which is invariably linked to factors such as sample processing and labeling (1).

It is universally accepted that RNA quality and quantity are of paramount importance for assuring the reliability and reproducibility of microarray results. The current gold standard for assessing total RNA quality is the ratio of $28 \mathrm{~S}: 18 \mathrm{~S}$ rRNA, which is observed following denaturing agarose gel electrophoresis. With appropriate standards, this method is also quantitative and is the only method that indicates the presence of contaminating DNA. Many different total RNA extraction methods are commercially available and each offers advantages. However, given the different extraction chemistries involved, we wanted to know if using the total RNA extraction method would impact the microarray gene expression results in ways that were unanticipated. To test this, we examined two of the most commonly used total RNA extraction chemistries and the utility of each of these to generate cDNA probes from limited samples for use with microarrays.

\section{MATERIALS AND METHODS}

\section{Cellular Sample}

Whole blood from the Centers for Disease Control and Prevention (CDC) donor services was collected into 8-mL citrate BD Vacutainer ${ }^{\mathrm{TM}}$ tubes (BD Vacutainer Systems, Franklin Lakes, NJ, USA). Peripheral blood mononuclear cells 
(PBMCs), leukocytes, and monocytes were isolated by using LSM $^{\circledR}$ Lymphocyte Separation Media (ICN Biomedicals, Costa Mesa, CA, USA). PBMCs from one anonymous healthy donor were used for the entire study. Washed cells were counted and frozen for viability in aliquots of $10 \times 10^{6}$ cells as previously described (2). The aliquots were stored in liquid nitrogen until RNA extraction.

\section{RNA Extraction}

Total RNA was extracted with two commonly used procedures. The first one, referred to as the single-step RNA extraction method, isolated total RNA by lysis of the cells in phenol and guanidine isothiocyanate, followed by the addition of chloroform and recovery of total RNA in the aqueous phase (3). The other, referred to as the glass filter method, requires cell lysis in a guanidinium thiocyanate solution, followed by total RNA isolation on an RNA binding glass filter (4). RNA quality and quantity were determined by denaturing agarose gel electrophoresis. The ratio of $28 \mathrm{~S}$ to $18 \mathrm{~S}$ rRNA bands and the concentration of the total RNA were determined by imaging the ethidium bromide-stained agarose gel using the Alpha Innotech Image Station and FluorChem ${ }^{\circledR} 2.0$ software (Alpha Innotech, San Leandro, CA, USA). DNA contamination was evaluated by the visual detection of a high molecular weight band in the gel.

In an experiment to evaluate different probe amounts, 7-10 $\mu \mathrm{g}$ total RNA were treated with $2 \mathrm{U}$ DNA-free $e^{\mathrm{TM}}$ DNase I enzyme (Ambion, Austin, TX, USA). In experiments to evaluate the effect of DNase treatment on the biotin labeling reaction, $3.5 \mu \mathrm{g}$ total RNA were treated with 2 U MessageClean ${ }^{\circledR}$ DNase I (GenHunter, Nashville, TN, USA), and the enzymatic reaction was heat-inactivated at $70^{\circ} \mathrm{C}$ for $10 \mathrm{~min}$. The quantity and quality of DNase-treated RNA were determined as described above.

\section{Probe Preparation and Hybridization to Microarrays}

One microliter of random hexamer primers $(3 \mu \mathrm{g} / \mu \mathrm{L})$ (Invitrogen, Carlsbad, CA, USA), $1 \mu \mathrm{L}$ oligo(dT) ${ }_{12-18}$ primer (0.5 $\mu \mathrm{g} / \mu \mathrm{L})$ (Invitrogen), $1 \mu \mathrm{L} \mathrm{dNTP}$ mixture (100 mM dGTP, dATP, dCTP, and $10 \mathrm{mM}$ dTTP) (Invitrogen), and 1 $\mu \mathrm{L}$ biotin-11-dUTP (1 mM) (Enzo, Farmingdale, NY, USA) were added to $1 \mu \mathrm{g}$ total RNA in $8 \mu \mathrm{L}$ DEPC-treated water (Ambion). This mixture was incubated at $65^{\circ} \mathrm{C}$ for $5 \mathrm{~min}$, and then $4 \mu \mathrm{L} 5 \times$ firststrand buffer, $2 \mu \mathrm{L} 0.1 \mathrm{M}$ dithiothreitol (DTT), and $1 \mu \mathrm{L}$ RNaseOUT ${ }^{\mathrm{TM}}$ Ribonuclease Inhibitor (all from Invitrogen) were added, and the mixture was incubated at $42^{\circ} \mathrm{C}$ for $2 \mathrm{~min}$. One microliter of

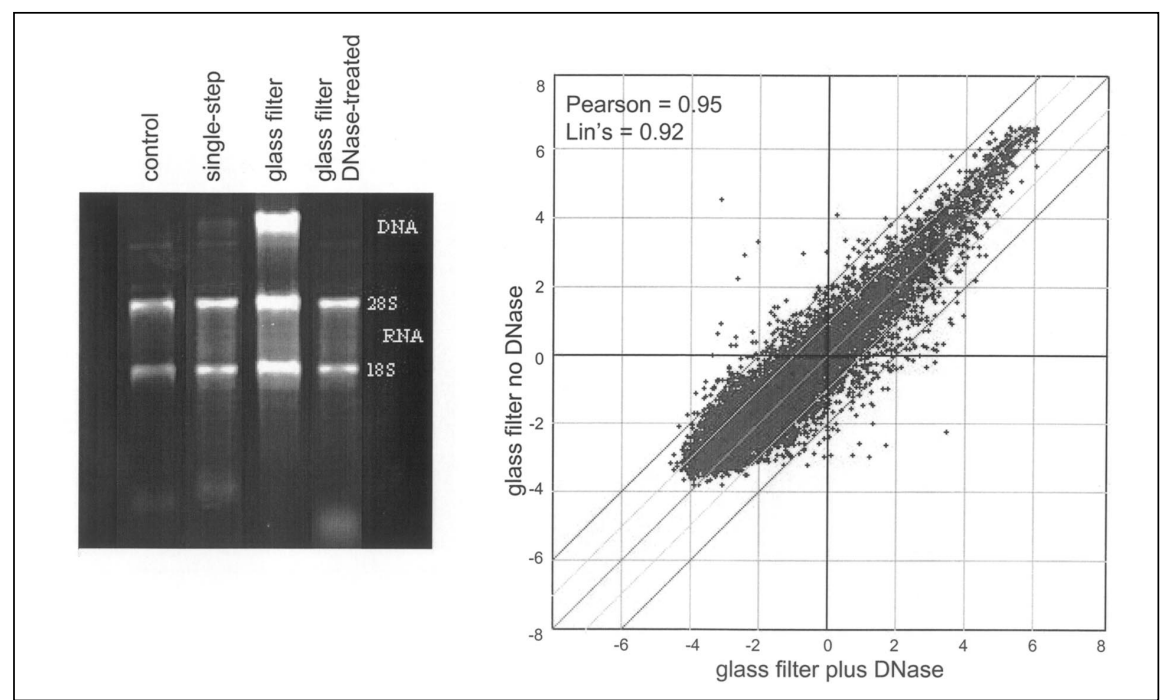

Figure 1. Visualization and evaluation of total RNA using two extraction methods and impact of residual DNA. (A) The yield and quality of the total RNA were compared with a standard control total RNA preparation. The $28 \mathrm{~S}$ and $18 \mathrm{~S}$ rRNA bands are indicated. A sample extracted with the glass filter approach is shown before and after DNase treatment. (B) Pairwise comparison of cDNA probes synthesized from DNase-treated ( $\mathrm{x}$-axis) and non-DNase-treated (y-axis) total RNA extracted with the glass filter method. Pearson correlation and Lin's concordance coefficients are shown. 
SUPERSCRIPT $^{\mathrm{TM}}$ II RNase $\mathrm{H}^{-}$(Invitrogen) was added and incubated at $42^{\circ} \mathrm{C}$ for 1 $\mathrm{h}$. The reverse transcription reaction was terminated by the addition of $2 \mu \mathrm{L} 2 \mathrm{M}$ $\mathrm{NaOH}$, followed by $15 \mathrm{~min}$ at $70^{\circ} \mathrm{C}$. The mixture was neutralized by the addition of $5 \mu \mathrm{L} 1 \mathrm{M}$ Tris-HCl, pH 7.4, and the labeled cDNA was purified using the QIAquick ${ }^{\circledR}$ PCR Purification Kit (Qiagen, Valencia, CA, USA). For technical replicate experiments, all of the labeled samples from one extraction method were pooled and aliquoted into $1-\mu \mathrm{g}$ (60 $\mu \mathrm{L})$ and $5-\mu \mathrm{g}(300 \mu \mathrm{L})$ samples. The volume of the $5-\mu \mathrm{g}$ sample was reduced to $60 \mu \mathrm{L}$ by vacuum centrifugation. The biotin-labeled cDNA probe was stored at $-20^{\circ} \mathrm{C}$ until use.

Pan ${ }^{\circledR}$ Human 10k Arrays (models A or C; MWG-Biotech, High Point, NC, USA) were prehybridized at $42^{\circ} \mathrm{C}$ for 45 min in $4 \times$ standard saline citrate (SSC), $0.5 \%$ sodium dodecyl sulfate (SDS), and $1 \mathrm{mg} / \mathrm{mL}$ bovine serum albumin (BSA). Sixty microliters of labeled cDNA sample were mixed with $140 \mu \mathrm{L}$ ChipHybe ${ }^{\mathrm{TM}}$ solution (Ventana Medical Systems, Tucson, AZ, USA) and denatured at $100^{\circ} \mathrm{C}$ for $2 \mathrm{~min}$ prior to hybridization. The denatured biotinylated cDNA from 1 or $5 \mu \mathrm{g}$ total RNA were hybridized to each array for $8 \mathrm{~h}$ at $42^{\circ} \mathrm{C}$ using the automated Discovery $^{\mathrm{TM}}$ System (Ventana Medical Systems) followed by $2 \times \mathrm{SSC}, 1 \times \mathrm{SSC}$, and $0.5 \times$ SSC stringency washes. Gold Resonance Light Scattering (RLS) Particles $^{\mathrm{TM}}$ with anti-biotin antibodies (gift of Genicon Sciences, San Diego, CA, USA) were used for detection. The microarrays were prepared for imaging and storage by dipping in archiving solution (gift of Genicon Sciences). The archived slides were scanned using the ICS-501 ${ }^{\mathrm{TM}}$ Image Capture Software version 2.1.3 (Genicon Sciences) to create TIFF images.

\section{Microarray Image Analysis}

The microarray TIFF images were quantified with Array Vision ${ }^{\mathrm{TM}}$ software (Imaging Research, St. Catherines, ON, Canada). For feature and background intensities, we used a corrected artifactremoved mean (ARM), calculated as the average of all pixels remaining in the feature or local background after the removal of pixels with values that exceeded four median absolute deviations above the median. Local background ARM was subtracted from feature ARM to give corrected values (sARM) for each feature. A feature was flagged if the percentage of removed or replaced pixels in the spot exceeded $10 \%$ of the total number of pixels in the spot (flagged features were omitted from analysis). The sARM values for each microarray were uploaded into CDC MADB, which is a Web-based microarray database analysis package.

\section{Analysis}

sARM values ranging between 0 and 65,000 pixels were calibrated to values between 0 and 100 and then $\log _{2}$-transformed. The $\log _{2}$ values were subsequently normalized to the 75 th percentile. For analyses of low and high probe amounts, $\log _{2}$-transformed values were not normalized to the 75 th percentile. Two technical replicates were used to evaluate each parameter. Histograms of the $\log _{2}$-sARM values were used to assess the overall signal distribution for each microarray experiment. Scatter plots of $\log _{2}$-sARM values were used to compare the similarity of the results using the Pearson correlation coefficient and the reproducibility of the method using the Lin's concordance coefficient (1).

\section{RESULTS}

\section{RNA Quality and DNase Treatment}

The recovery of total RNA from 10 $\times 10^{6}$ PBMCs was 7-10 $\mu \mathrm{g}$ for both extraction approaches (Figure 1A). Each extraction method yielded good quality total RNA, with $28 \mathrm{~S}$ to $18 \mathrm{~S}$ rRNA ratios ranging from 1.11 to 1.40 . The gel image (Figure 1A) illustrates the frequent occurrence of residual DNA following extraction using the glass filter method and the resulting DNA-free RNA following DNase treatment.

To determine if residual DNA would affect the probe synthesis and reliable interpretation of microarray results, a cDNA probe synthesized from non-DNase-treated total RNA was compared with one synthesized from DNase-treated total RNA. There was a high degree of similarity, with $98 \%$ of all spot intensities within the 4-fold line, which indicates that the residual DNA has little effect in the cDNA probe synthesis (Figure 1B).

\section{Experimental Variability}

Technical replicate microarray experiments were compared to assess the experimental variability of the extraction methods and cDNA probe concentrations. A small number of genes fell outside the 4-fold lines for the single-step RNA extraction method $[75$ (1\%) for 1 and 56 $(0.6 \%)$ for $5 \mu \mathrm{g}]$. Both $1-$ and $5-\mu \mathrm{g}$ cDNA probes synthesized with single-step extracted RNA had high Pearson correlation coefficients (0.96 and 0.97, respectively) and high concordance (Lin's concordance coefficients, 0.95 and 0.96 , respectively). Slightly more genes fell outside the 4-fold lines for both probes synthesized from glass filter-extracted total RNA [165 (2\%) for 1 and $80(0.8 \%)$ for $5 \mu \mathrm{g}]$. The Lin's concordance coefficients were also less (0.88 for 1 and 0.94 for $5 \mu \mathrm{g}$ ). Accordingly, more discrepancies were observed with replicates generated from both concentrations of the total RNA extracted using the glass filter approach. 


\section{Probe Concentration}

We hybridized microarrays with cDNA probes synthesized from 1 and 5 $\mu \mathrm{g}$ total RNA to determine if low probe amounts would maintain the same gene expression profile as the higher amounts. The 5- $\mu \mathrm{g}$ cDNA probe resulted in overall mean signal intensities higher than those achieved with the $1-\mu \mathrm{g}$ cDNA probe (2685 versus 1730 pixels). Despite the differences in overall intensity, the $1-\mu \mathrm{g}$ cDNA probe gene expression profile was very similar to the 5- $\mu \mathrm{g}$ cDNA probe, with Pearson correlation coefficients of
0.95 (single-step method) and 0.94 (glass filter method) and Lin's concordance coefficients of 0.87 and 0.86 , respectively. Total RNA extracted with the singlestep method resulted in less scatter and slightly greater similarity compared with results from total RNA extracted with the glass filter. The lower Lin's concordance coefficients caused by a shift from the $45^{\circ}$ identity line occurred because the overall signal intensity was greater with the $5-\mu \mathrm{g}$ cDNA probes than with the $1-\mu \mathrm{g}$ cDNA probes (Figure 2A). A histogram of signal intensities generated for both probe concentrations illustrates a greater dynamic

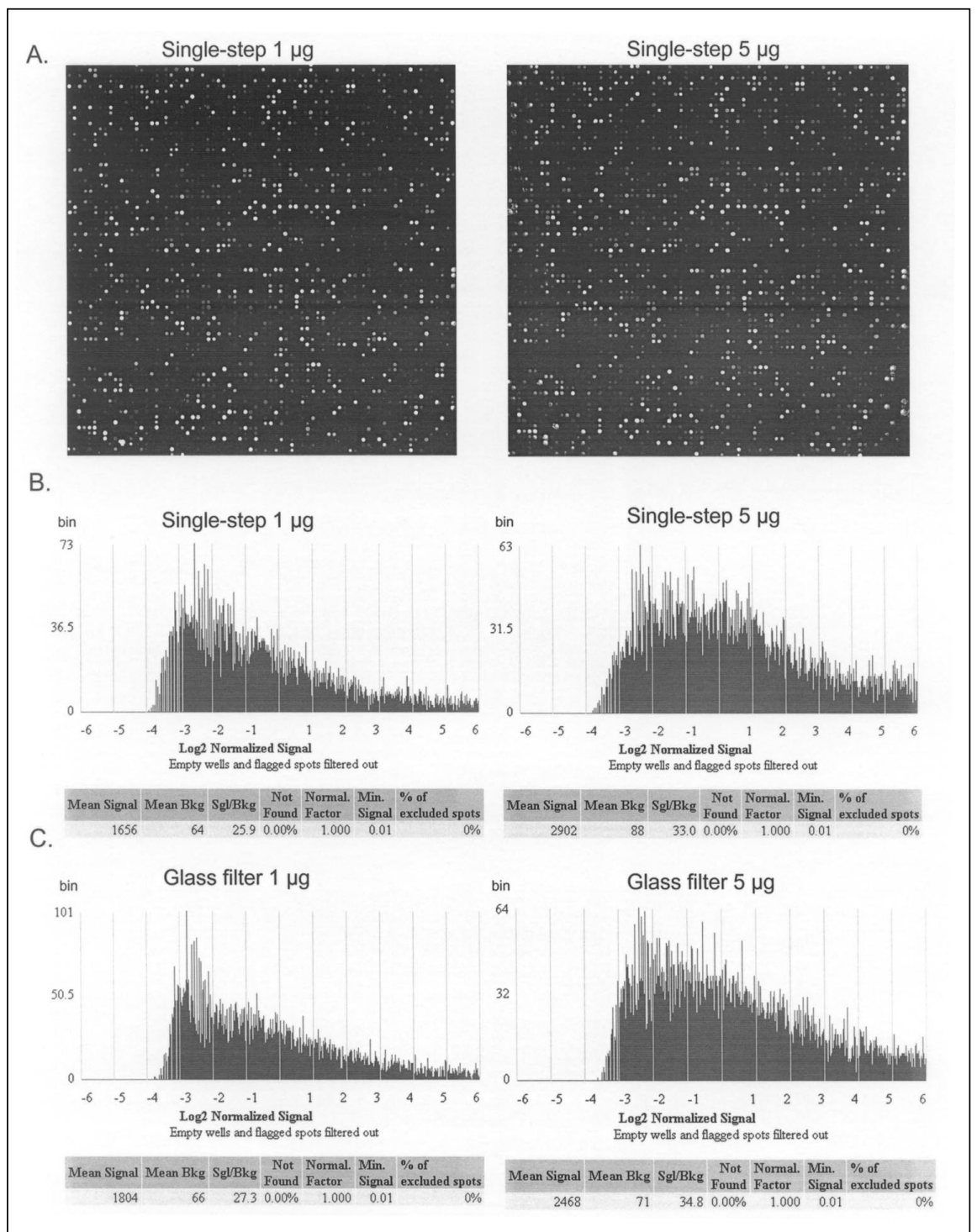

Figure 2. Signal distribution varies with sample concentration. The histograms represent the signal distribution of the intensity values for averaged calibrated technical replicate experiments for low and high cDNA probe concentrations ( 1 and $5 \mu \mathrm{g}$ total RNA) using (A) the single-step method and (B) the glass filter method. The histograms highlight the differences between the two probe concentrations for both RNA extraction methods. Bkg, background; sgl, signal; normal., normalization; min., minimum. 
range of high-intensity genes with the 1$\mu \mathrm{g}$ cDNA probes, and a greater dynamic range for the low-intensity genes with the $5-\mu \mathrm{g}$ cDNA probes for probes synthesized from the single-step (Figure 2B) and the glass filter (Figure 2C) methods.

\section{Extraction Method Comparison}

We compared the cDNA probes synthesized from RNA that had been extracted using both methods. The correlation was equally high for both low and high cDNA probe concentration comparisons (Figure 3, high concentration; data not shown). For both comparisons, only $1 \%$ of the genes fall outside the 4-fold lines, which is within the experimental error.

\section{DISCUSSION}

Perhaps the greatest strides in understanding disease will come from the application of powerful genomics technologies to clinical samples. How- ever, ironically, we are only now facing the challenges posed by dealing with clinical samples as a molecular biopsy. Diseased tissues are limited in size and must be used sparingly to conserve material for both diagnostic and research purposes. Peripheral blood is an attractive alternative sample to serve as the molecular biopsy because it is relatively noninvasive and likely reflects ongoing systemic processes. Here and in previous studies $(2,5)$, we have shown that 5-10 $\mu$ g good-quality RNA can be obtained from an 8-mL blood draw.

The quality of the RNA is important to consider when using microarray technology because this is the material that is used to generate the probe. This probe is meant to reflect the gene expression profile in a sample; therefore, poorly processed or partially degraded samples may not faithfully represent transcription (6). Several different total RNA extraction methods are available, and two of the most commonly used approaches have been tested here. Both extraction methods yielded good-quality total RNA. Total RNA extracted using the glass filter approach often required DNase treatment, while the single-step method yielded total RNA with very little DNA contamination. The DNase treatment of total RNA extracted with the glass filter method is effective at removing contaminating DNA, but the same is not true for total RNA extracted with the single-step approach. Because the single-step approach yields total RNA in the aqueous phase, with little to no DNA contamination, DNase treatment results in the degradation of RNA (data not shown). There was little effect of residual DNA on cDNA probe synthesis, although both the Pearson correlation and Lin's concordance coefficients were slightly lower for the technical replicate microarray results generated using the glass filter method. This may be due to subtle alterations in the RNA on DNase treatment. While residual DNA had only a minor effect on the microarray results shown here, the presence of DNA would affect a probe synthesis approach that used amplification and would clearly impact validation experiments using reverse transcription PCR (RT-PCR).

Most microarray methods require 5$100 \mu \mathrm{g}$ total RNA to synthesize the probe. In vitro transcription is commonly used to synthesize the probe and has been shown to be reproducible and representative using high-quality RNA $(7,8)$. However, in vitro transcription is a time-consuming, linear amplification method that is likely to vary using a variety of sources of clinical samples. We have shown that a simple reverse transcription for cDNA probe synthesis is effective at producing a reproducible and reliable probe for use with microarrays (1). Our results show that this probe synthesis approach works on small amounts of total RNA. The RLS system used in this study employs gold particles for detection and is significantly more sensitive than fluorescent systems that facilitate the use of considerably lower sample amounts (9). This in turn allows for further experimentation on the remaining total RNA sample, including the validation of differentially expressed genes (10).

The variability among the experiments is less than $1.9 \%$ and is likely

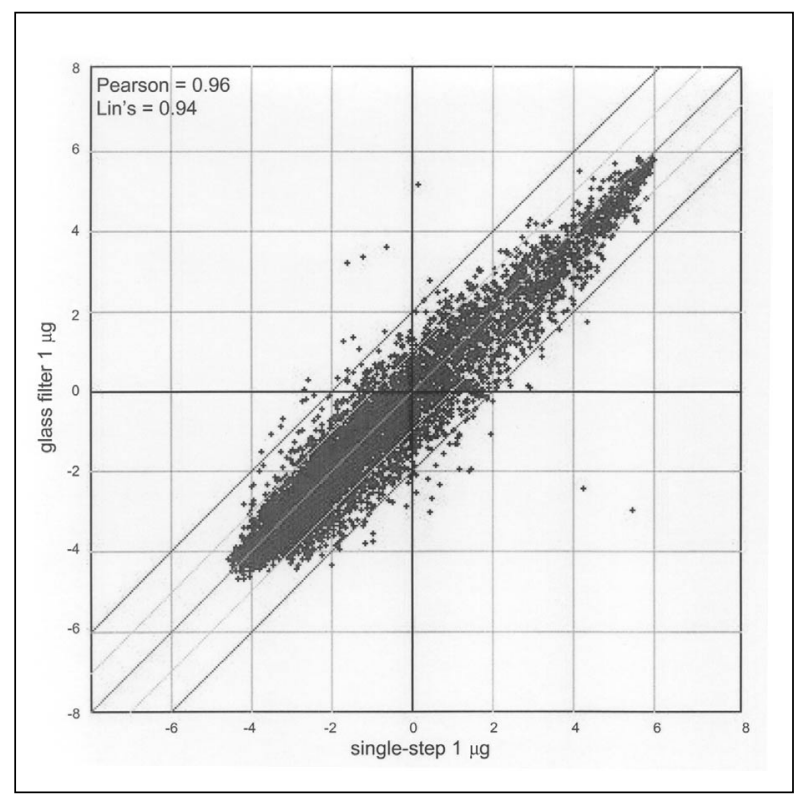

Figure 3. Impact of RNA extraction method on gene expression results. The scatter plot shows a high correlation between experiments using the same sample concentration $(1 \mu \mathrm{g})$ with each extraction method (high concentration; data not shown). The experiments were averaged and normalized. Pearson correlation and Lin's concordance coefficients are shown. 
due to the fact that the cDNA synthesis approach is efficient and requires few manipulations. Also, automated hybridization reduces human handling and provides superior and efficient control of hybridization conditions (e.g., temperature and mixing). Reproducibility of microarray results for technical replicates of the same sample is required if the detection of differential gene expression between samples is to be achieved.

While our results indicate that experiments with different mean signal intensities are difficult to compare, new normalization mathematics are making this possible (11). However, to minimize the variability of results within a study, it is important to use probe concentrations as similar as possible for all hybridizations. Although the gene expression profiles generated by the two RNA extraction approaches are very similar, the use of a single method is preferred to reduce variability.

In summary, when good-quality microarrays are hybridized with high-quality RNA, the RNA extraction method has little impact on the gene expression results. Although some extraction methods yield RNA with more contaminating DNA, this does not seem to dramatically affect reverse transcription for cDNA probe synthesis. The use of a sensitive detection system, such as the RLS system, allows for small amounts of total RNA to be used reliably in microarray experiments. These experiments were conducted to provide information that will allow the field to move toward the standardization of microarray methods for use with clinical samples and to illustrate that microarray technology holds great promise for the use of clinical samples in the diagnostic setting.

\section{ACKNOWLEDGMENTS}

This work was supported in part by an agreement between the Centers for Disease Control and Prevention (CDC) and Genicon Sciences for the use and $\beta$ testing of the Resonance Light Scattering System. This work was also supported in part by the National Cancer Institute's Early Detection Research Network (EDRN), Interagency Agreement no. Y1-CN-010101. Ms. Ojaniemi is a predoctoral fellow supported by the Karolinska Institute, the Royal Institute of Technology, and the Centers for Disease Control and Prevention. We thank Dr. Toni Whistler for her thoughtful discussions and advice.

\section{REFERENCES}

1.Vernon S.D., E.R. Unger, M. Rajeevan, I.M. Dimulescu, R. Nisenbaum, and C.E. Campbell. 2000. Reproducibility of alternative probe synthesis approaches for gene expression profiling with arrays. J. Mol. Diagn. 2:124-127.

2.Campbell, C., S.D. Vernon, K.L. Karem, R. Nisenbaum, and E.R. Unger. 2002. Assessment of normal variability in peripheral blood gene expression. Dis. Markers 18:201-206.

3.Chomczynski P. and N. Sacchi. 1987. Singlestep method of RNA isolation by acid guanidinium thiocyanate-phenol-chloroform extraction. Anal. Biochem. 162:156-159.

4.Gadbois, D.M., W.L. Salo, D.K. Ann, S.W. Downing, and D.M. Carlson. 1988. The preparation of poly (A) + mRNA from the hagfish slime gland. Prep. Biochem. 18:67-76.

5.Vernon, S.D., E.R. Unger, I.M. Dimulescu, M. Rajeevan, and W.C. Reeves. 2002. Utility of the blood for gene expression profiling and biomarker discovery in chronic fatigue syndrome. Dis. Markers 18:193-199.

6.Hedge, P., Q. Rong, K. Abernathy, C. Gay, S. Dharap, R. Gaspards, J. Earle-Hughes, E. Snesrud, et al. 2000. A concise guide to cDNA microarray analysis-II. BioTechniques 29:548-562.

7.Puskas, L.G., A. Zvara, L. Hackler Jr., and P. Van Hummelen. 2002. RNA amplification results in reproducible microarray data with slight ratio bias. BioTechniques 32:1330-1340.

8.Zhao, H., T. Hastie, M.L. Whitfield, A.L. Borresen-Dale, and S.S. Jeffrey. 2002. Optimization and evaluation of T7 based RNA linear amplification protocols for cDNA microarray analysis. BMC Genomics 3:31.

9.Bao, P., A.G. Frutos, C. Greef, J. Lahiri, U. Muller, T.C. Peterson, L. Warden, and X. Xie. 2002. High-sensitivity detection of DNA hybridization on microarrays using resonance light scattering. Anal. Chem. 74:1792-1797.

10.Rajeevan, M.S., D.G. Ranamukhaarachchi, S.D. Vernon, and E.R. Unger. 2001. Use of real-time quantitative PCR to validate the results of cDNA array and differential display PCR technologies. Methods 25:443-451.

11.Cheadle, C., M.P. Vawter, W.J. Freed, and K.G. Becker. 2003. Analysis of microarray data using $\mathrm{Z}$ score transformation. J. Mol. Diagn. 5:73-81.

Received 26 June 2003; accepted 26 August 2003.

Address correspondence to Suzanne D. Vernon, Centers for Disease Control and Prevention, 1600 Clifton Road, Mail Stop A-15, Atlanta, GA 30333, USA. e-mail: svernon@cdc.gov 